\title{
Multiple Large Pyogenic Granulomas Overlying a Burn: Case Report and Literature Review
}

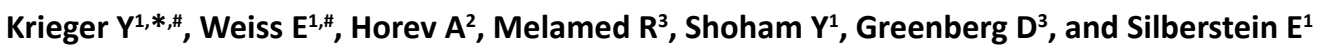 \\ ${ }^{1}$ Department of Plastic and Reconstructive surgery, Soroka University Medical Centre and the faculty of Health Sciences, Ben-Gurion University of \\ Negev, Beer-Sheva, Israel \\ ${ }^{2}$ Pediatric dermatology service, Soroka University Medical Centre and the faculty of Health Sciences, Ben-Gurion University of Negev, Beer-Sheva, Israel \\ ${ }^{3}$ PediatricDivision, Soroka University Medical Centre and the faculty of Health Sciences, Ben-Gurion University of Negev, Beer-Sheva, Israel \\ \#Y. Krieger and E. Weiss contributed equally to this work
}

*Corresponding author: Krieger $Y$, Department of Plastic and Reconstructive surgery, Soroka University Medical Centre and the faculty of Health Sciences, Ben-Gurion University of Negev, Beer-Sheva, Israel; Tel: +972-8-6400880; Fax: +972-8-6403033; E-mail: dr.krieger@gmail.com

Received: 29 Sep, 2020 | Accepted: 22 Oct, 2020 | Published: 29 Oct, 2020

Citation: Krieger Y, Weiss E, Horev A, Melamed R, Shoham Y, et al. (2020) Multiple Large Pyogenic Granulomas Overlying a Burn: Case Report and Literature Review. J Clin Cosmet Dermatol 4(3): dx.doi.org/10.16966/2576-2826.155

Copyright: (C) 2020 Krieger Y, et al. This is an open-access article distributed under the terms of the Creative Commons Attribution License, which permits unrestricted use, distribution, and reproduction in any medium, provided the original author and source are credited.

\section{Abstract}

Pyogenic granuloma is a vascular lesion of the skin commonly found in children and young adults. It is known to erupt following skin laceration or penetrating injury, but is only rarely reported in children after a burn injury.

In this report we present an unusual presentation of large multiple pyogenic granuloma lesions following a scald burn in a 17-month old child and review thespars literature on the subject.

This phenomenon may represent a severe form of hypergranulation developing in dermal burns allowed for spontaneous healing.

Keywords: Pyogenic Granuloma; Burn; Scald; Children; Paediatric

\section{Case Report}

A 17-month old boy was brought to the emergency room with a $2^{\text {nd }}$ degree burn of his face, chest, right upper and lower extremities. The burn wounds spanned a total body surface area of approximately $6 \%$. The mother accounted that the child was injured from hot boiling water. On admission, he was treated with supportive therapy which included intravenous $\mathrm{NaCl} 0.45 \%+5 \%$ dextrose and $\mathrm{KCL}$ $0.149 \%$ together with paracetamol for analgesia. The temperature on admission was $36.4^{\circ} \mathrm{C}$. In the first few days of his stay, the child suffered from high fever up to $39^{\circ} \mathrm{C}$ with no signs of infection (WBC count with in normal values, sterile blood cultures). The burn wounds were treated with topical antibiotics dressings (chloramphenicol 3\%). After two weeks of daily follow-up and treatment, an advanced closure of the burn areas was observed (approximately 90\% epithelization) and the patient was discharged to continue his follow up in the outpatient burn clinic.

One week after his discharge, the patient's parents noticed the appearance of a few new raised round lesions on his forearm. After waiting an additional week, the boy was referred to the emergency room by his pediatrician. On physical examination, several round raised nodular lesions with an erythematous glistening surface with patchy necrotic areas covered with yellowish-brown crust were noted.
The lesions were $0.8-3 \mathrm{~cm}$ in diameter, located at the medial aspect of the right arm, forearm and dorsum of the wrist within the previously scalded area (Figure 1 and 2).

Blood and swab wound cultures were taken [no eventual bacterial growth] and systemic antibiotic treatment was initiated with intravenous amoxicillin/clavulonate. His wounds were treated locally with dressings soaked with Mafenide Acetate 5\%.

Tissue biopsy taken on admission demonstrated lobulated proliferation of capillary sized vessels in an edematous stroma with inflammatory characteristics and confirmed the diagnosis of Pyogenic Granuloma (PG) (Figure 3). The patient underwent surgery to remove those granulomatous lesions. The defects created were coverd using a split thickness skin graft. The child was discharged with the skin grafts fully taken. He continued his follow up in the outpatient burn clinic until complete recovery. All areas which underwent excision and skin grafting, have demonstrated complete graft take and no signs of recurrence of the granulomatous lesions during that time (Figure 4).

\section{Discussion and Literature Review}

Pyogenic Granuloma (PG), also known as lobular capillary hemangioma or granuloma telangiectaticumis a common, acquired, benign vascular tumor, with mutations reported in the BRAF/RAS/ 


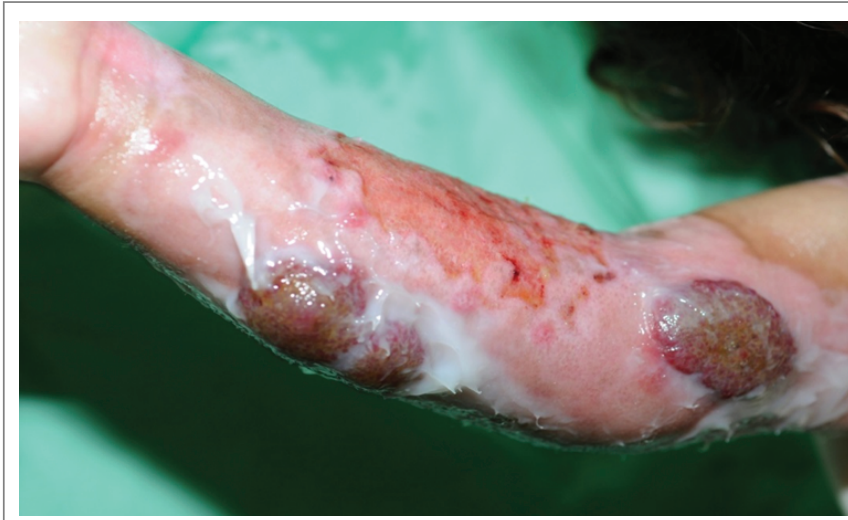

Figure 1: Right forearm volar aspect 3 weeks post burn with newly formed cutaneous lesions.

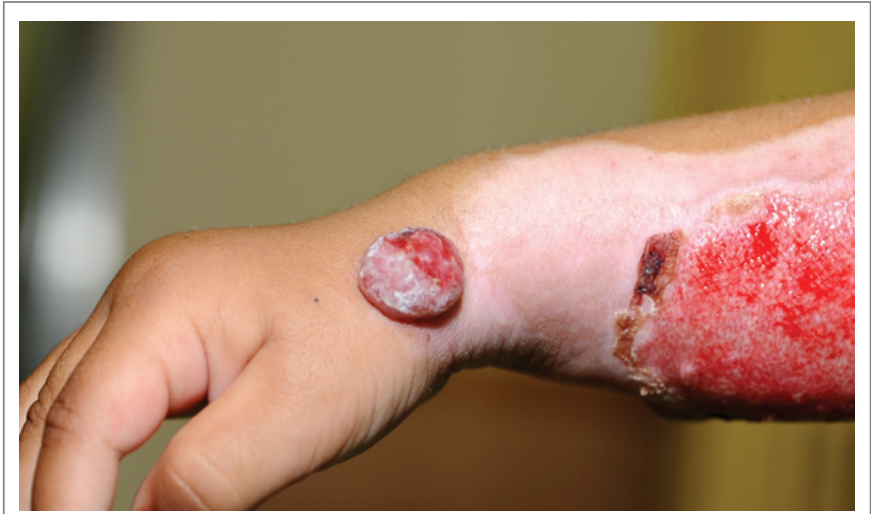

Figure 2: Right Forearm dorsal aspect 3 weeks post burn with newly formed cutaneous lesions.

GNA14 genes. Pyogenic granulomas appear as red fleshy papules, which are typically round or oval raised flexible lesions that occurs most commonly on the acral skin. It grows rapidly, erupting through the skin forming a stalk or pedicle. Size ranges from a few millimeters to centimeters; however they are usually small with an average diameter of $6.5 \mathrm{~mm}$.

This type of skin capillary lesion is most commonly seen in children with a mean age of 6.7 years, with a 2:1 male to female ratio [1]. PG primarily involves the skin; however, it can also involve the mucus membranes as seen on the gingiva of pregnant woman. Histologically, a lobular capillary hemangioma characterized by lobulated proliferation of capillary sized vessels in a loose and edematous stroma with inflammatory characteristics. The lesion stains positive for vascular markers like CD31, CD34, and factor VIII antigen, but unlike infantile hemangioma, are negative for glucose transporter-1 (GLUT1).The pathognemoniclobular arrangement of capillaries distinguishes it histologically from granulation tissue. It has even been reported to appear following trauma, infection, dermatoses and on Port-wine stains [2]. As the etiology has not yet been determined PG is suspected to represent an abnormal healing process with hyperplastic neovascularization response to angiogenic stimulus due to imbalance of promoters and inhibitors. Thus, is supported by evident high levels of growth factors such as Vascular Endothelial Growth Factor (VEGF), Fibroblast Growth Factor (FGF) and over expression of some transcription factors. Trauma is considered to be the major risk factors

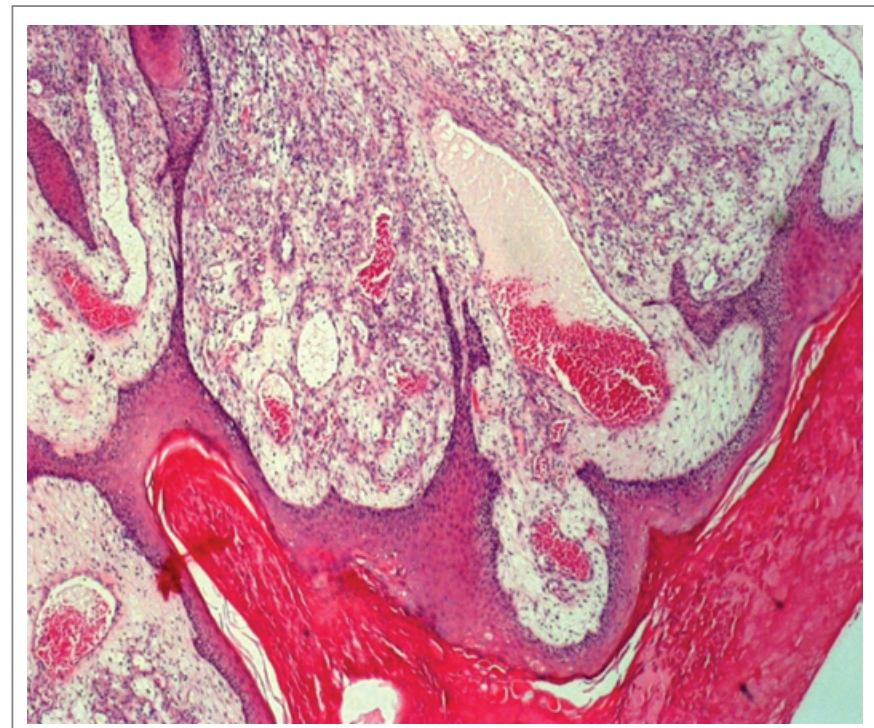

Figure 3: Histologic examination demonstrating lobulated proliferation of capillary sized vessels with inflammatory characteristics diagnostic of PG. (H\& E staining; magnification 10x)

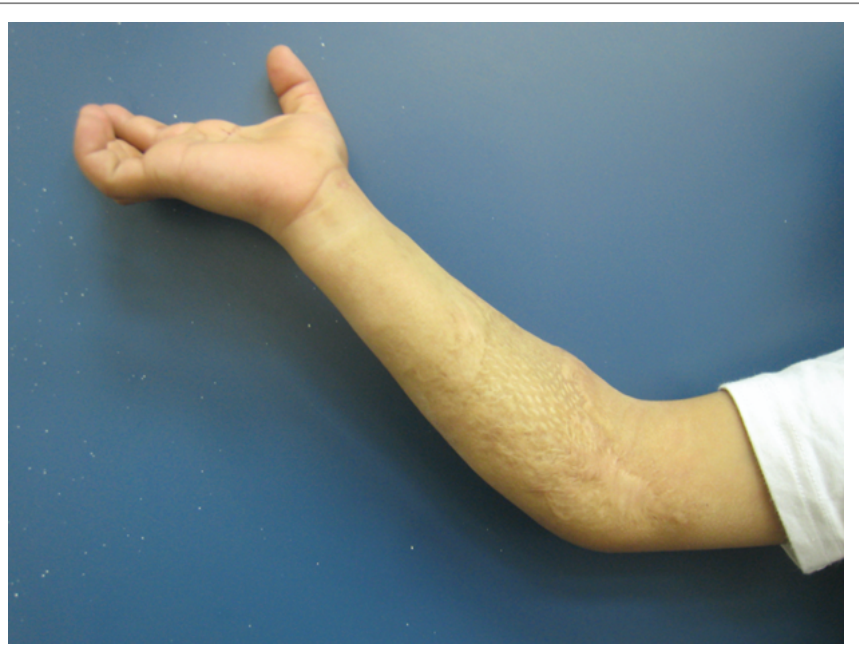

Figure 4: 3 years following skin grafting of proximal forearm.

in the pathogenesis of PG, since trauma or local surgical treatment procedure often precede the lesion's appearance. Increased levels of female sex hormones and unidentified microorganisms such us bacteria [3], fungi and viruses that invade interrupted skin barrier are also suggested to be a possible trigger. The most common complications caused by pyogenic granuloma are bleeding and ulceration.

The differential diagnosis of pyogenic granuloma includes many benign and malignant lesions such as: amelanotic Melanoma, Angiosarcoma, Basal cell carcinoma, Kaposi sarcoma, hemangioma, bacillary angiomatosis, metastatic visceral malignancies, and granulation tissue $[4,5]$.

Treatment options include: surgical excision with primary closure, shave excision at the base followed by electrocautery, cryotherapy with liquid nitrogen, carbon dioxide $\left(\mathrm{CO}_{2}\right)$ laser vaporization, pulsed dye laser therapy, electro-coagulation, local antibiotics and even supportive treatment alone were used and demonstrated favorable outcomes [6-8]. 
Table 1: Cases pf pyogenic granuloma in children literature review.

\begin{tabular}{|c|c|c|c|c|c|}
\hline & Year & Age & Sex & Etiology & Location \\
\hline De Kaminsky, et al. [13] & 1978 & $15 \mathrm{~m} / \mathrm{o}$ & $\mathrm{F}$ & Boiling Milk & Trunk \\
\hline \multirow{3}{*}{ Momeni AZ, et al. [11] } & \multirow{3}{*}{1995} & $1.5 y / o$ & $\mathrm{M}$ & Boiling Milk & Trunk \\
\hline & & $5 y / 0$ & $\mathrm{~F}$ & Boiling Milk & Trunk \\
\hline & & $35 y / 0$ & $\mathrm{~F}$ & Boiling Milk & Trunk \\
\hline Ceyhan M, et al. [12] & 1997 & $18 \mathrm{~m} / \mathrm{o}$ & $\mathrm{F}$ & Boiling Milk & Arm \\
\hline Aliagaoglu, et al. [1] & 2006 & $5 y / 0$ & $\mathrm{~F}$ & Unknown & Arm \\
\hline Bozkurt M, et al. [10] & 2006 & $2 y / 0$ & $M$ & Boiling Milk & Forearm \\
\hline Ceyhan, et al. [12] & 2007 & $12 y / o$ & $\mathrm{M}$ & Boiling Hot Water & Arm \\
\hline Ozbayoglu, et al. & 2011 & $8 y / 0$ & $\mathrm{M}$ & Flame & Trunk \\
\hline \multirow{2}{*}{ Drugun M, et al. [14] } & \multirow{2}{*}{2013} & $2 y / 0$ & $\mathrm{~F}$ & Unknown & Face \\
\hline & & $7 y / 0$ & M & Boiling Hot Water & Forearm \\
\hline
\end{tabular}

A total number of 11 cases of PG lesions following burn injury were allocated by web search of Pubmed and Google Scholar (Table 1). Six of all the cases reported were caused by hot boiling milk [9-14].

Complete healing with no recurrence was demonstrated in all cases which were followed for 6 to 12 months. Patrice et al studied the outcome of a sample of 178 pediatric patients that developed PG subsequent to different conditions such as: preexisting capillary stains, dermatologic disorders, insect bites, and trauma. This study reported that there were no recurrences after full-thickness excision; however, a $43.5 \%$ recurrence rate was noted for lesions treated by cautery alone or by tangential excision and cautery. One group reported a case of PG lesion, developed on the burned skin of a 17-month-old boy, which resolved with oral erythromycin treatment for 8 weeks [15].

The etiology of PG following a burn injury remains unclear. Bozkurt $\mathrm{M}$, et al. [10] assumed that either proteins or other milk components may have contributed to the development of PG. Several investigators hypothesized that it is a hyperproliferative vascular response to infective organisms that are bacterial, viral or even fungal in nature. Some regard it as a disorder of angiogenesis with a neovascular response to an angiogenic stimulus, promoting predominant growth of pericytes with less effect on endothelial cells. We postulate that PG in response to burn wound may represent a severe form of hypergranulation, a phenomenon often found in healing burn wounds. In all cases described, pyogenic granuloma appeared on area of a second degree burn injury treated conservatively to allow spontaneous healing of which the proliferation of granulation tissue is an integral part. It is possible that a first degree burn injury is not severe enough to induce such an inflammatory and neovascularization process, while on the other hand, a deeper third degree burn injury is usually treated surgically, not allowing the formation of granulation tissue. The abundant vascularization found in the hands and face could be related to the abundance of PG appearance found in these areas.

\section{Conclusion}

Pyogenic granuloma is a common complication of trauma, with rare occurrence following a burn injury. It has been reported to occur in scaled burns caused by hot milk or boiling water in only few children. It was suggested that milk proteins may promote its development; this however is a hypothesis that has no additional support. We think this phenomenon may represent a severe form of hypergranulation developing in dermal burns allowed for spontaneous healing.

\section{Acknowledgement}

Ignacio Sztarkier MD, Leonid Kachko MD, The department of Pathology, Soroka university medical center.

\section{Conflict of Interest}

The authors have no conflict of interest to declare

\section{Financial Support}

The study received no financial support.

\section{References}

1. Aliağaoğlu C, Bakan V, Atasoy M, Toker S (2006) Pyogenic granuloma with multiple and satellite involvement after a burn in a 5-year-old child. J Dermatol 33: 150-152.

2. Askar I, KIlınc N, Yucetas A (2003) Pyogenic granuloma appearing on Port-wine stain: a case report. Acta Chir Plast 45: 52-54.

3. Lee J, Lynde C (2001) Pyogenic granuloma: pyogenic again? Association between pyogenic granuloma and Bartonella. J Cutan Med Surg 5: 467-470.

4. Itin PH, Fluckiger R, Zbinden R, Frei R (1994) Recurrent pyogenic granuloma with satellitosis-a localized variant of bacillary angiomatosis? Dermatology 189: 409-412.

5. Lin RL, Janniger CK (2004) Pyogenic granuloma. Cutis 74: 229-233.

6. Money MA, Janniger CK (1995) Pyogenic granuloma. Cutis 55: 123136.

7. Partice SJ, Wiss K, Mulliken JB (1991) Pyogenic granuloma (lobular capillary hemangioma). A clinicopathologic study of 178 cases. Pediatr Dermatol 8: 267-276.

8. Pagliai KA, Cohen BA (2004) Pyogenic granuloma in children. Pediatr Dermatol 21: 10-13.

9. Netscher D, Spira M, Cohen V (2000) Nonhemangiomatous vascular lesions. In: Achauer BM (eds) Plastic Surgery Indications, Operations and Outcomes. $1^{\text {st }}$ Edition, Mosby, Missouri, USA 310.

10. Bozkurt M, Kulahci Y, Zor F, Askar I (2006) Multiple giant disseminated pyogenic granuloma in a burn lesion. J Burn Care Res 27: 247-249.

11. Momeni AZ, Enshaieh S, Sodifi M, Aminjawaheri M (1995) Multiple giant disseminated pyogenic granuloma in three patients burned by boiling milk. Int J Dermatol 34: 707-710. 
12. Ceyhan M, Erdem G, Kotiloğlu E, Kale G, Talim B, et al. (1997) Pyogenic granuloma with multiple dissemination in a burn lesion. Pediatr Dermatol 14: 213-215.

13. de Kaminsky AR, Otero AC, Kaminsky CA, Shaw M, Formentini E, et al. (1978) Multiple disseminated pyogenic granuloma. Br J Dermatol 98: 461-464.

14. Durgun M, Selcuk CT, Ozalp B, Aydinol M, Alabalik U (2013) Multiple disseminated pyogenic granuloma after second degree scald burn: a rare two case. Int J Burns Trauma 3: 125-129.

15. Ceyhan AM, Basak PY, Akkaya VB, Yildirim M, Kapucuoglu N (2007) A case of multiple, eruptive pyogenic granuloma developed on a region of the burned skin: can erythromycin be a treatment option? J Burn Care Res 28: 754-757. 